DOI: https://doi.org/10.24297/jam.v20i.9077

\title{
Triads Of Metallic Ratios, The Mathematical Relations between different Metallic Means, And Geometric Substantiation of Metallic Numbers with the Right Angled Triangles
}

\author{
Dr. Chetansing Rajput \\ M.B.B.S. Nair Hospital (Mumbai University) India, \\ Asst. Commissioner (Govt. of Maharashtra) \\ Email: chetansingkrajput@gmail.com \\ Website: https://goldenratiorajput.com/ \\ Lecture Link 1 : https://youtu.be/vBfVDaFnA2k \\ Lecture Link 2 : https://youtu.be/74uF4sBqYjs \\ Lecture Link 3 : https://youtu.be/raosniXwRhw \\ Lecture Link 4 : https://youtu.be/Qh2B1tMl8Bk
}

\begin{abstract}
This paper synergizes the newly discovered geometry of all Metallic Means and the recently published mathematical formulae those provide the precise correlations between different Metallic Ratios. The paper also illustrates the concept of the "TRIADS of Metallic Means". The Metallic Means and their TRIADS can be geometrically substantiated, in an intriguing manner, as described herein.
\end{abstract}

Keywords: Metallic Mean, Pythagoras Theorem, Fibonacci, Pell, Lucas, Pi, Phi, Silver Ratio, Right Triangle, Metallic Numbers, Metallic Ratio Triads, 36 9, Pythagorean Triples, Bronze Ratio, Golden Ratio, Pascal's Triangle, Metallic Ratio

\section{Introduction}

This paper brings together following, recently discovered, new aspects of Mertallic Ratios.

1) The Generalised Geometric Construction of all Metallic Ratios: cited by the Wikipedia page: "Metallic Mean" [6]. This generalised geometric substantiation of all Metallic Means was published in January 2021 [7]

2) The Mathematical Formula that provides the precise correlation between different Metallic Means. This explicit formula has been recently published in the month of May 2021 [1].

These couple of important aspects of Metallic Means: viz. the generalised geometric constructions of all Metallic Means and the concerned mathematical formulae, were brought together in the work mentioned in Reference [2].

The prime objective of current paper is to further synergize the these two newly discovered aspects of Metallic Means.

The synergism between above two features of Metallic Means unveils an intriguing pattern of Metallic Ratios, which asserts that the mathematical implications of these Means have not been fully appreciated so far. The abovementioned Geometry and Mathematics synergically enable us to recognize the full worth of these Metallic Means, as described in this paper.

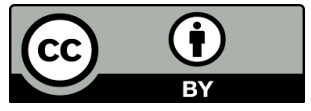


As a brief introduction, each Metallic Mean $\boldsymbol{\delta}_{\mathbf{n}}$ is the root of the simple Quadratic Equation $\mathbf{X}^{\mathbf{2}}-\mathbf{n} \mathbf{X}-\mathbf{1}=\mathbf{0}$, where $\mathbf{n}$ is any positive natural number.

Thus, the fractional expression of the $\mathrm{n}^{\text {th }}$ Metallic Ratio is $\boldsymbol{\delta}_{n}=\frac{\mathbf{n}+\sqrt{\mathbf{n}^{2}+\mathbf{4}}}{\mathbf{2}}$

Moreover, each Metallic Ratio can be expressed as the continued fraction:

$\boldsymbol{\delta}_{\mathbf{n}}=\mathbf{n}+\frac{\mathbf{1}}{\mathbf{n}+\frac{\mathbf{1}}{\mathbf{n}+\frac{1}{\mathbf{n}+\ldots}}} ;$ And hence, $\boldsymbol{\delta}_{\mathbf{n}}=\mathbf{n}+\frac{\mathbf{1}}{\boldsymbol{\delta} \mathbf{n}}$

.....References: [3], [4], [5]

\section{GEOMETRIC CONSTRUCTION OF ALL METALLIC MEANS :}

Each Metallic Ratio can be constructed geometrically with a special Right Angled Triangle. Any $\mathrm{n}^{\text {th }}$ Metallic Mean can be represented by the Right Triangle having its catheti $\mathbf{1}$ and $\frac{\mathbf{n}}{\mathbf{2}}$. Hence, the right triangle with one of its catheti $=\mathbf{1}$ may substantiate any Metallic Mean, having its second cathetus $=\frac{\mathbf{n}}{\mathbf{2}}$, where $\mathrm{n}=1$ for Golden Ratio, $\mathrm{n}=2$ for Silver Ratio, $n=3$ for Bronze Ratio, and so on. Such Right Triangle provides the precise value of $n^{\text {th }}$ Metallic Mean by the generalised formula:

$$
\text { The } n^{\text {th }} \text { Metallic Mean }\left(\boldsymbol{\delta}_{n}\right)=\text { Hypotenuse }+ \text { Cathetus } \frac{n}{2}
$$

Such Right Triangle not only provides for the accurate geometric construction and precise fractional expression of any $\mathrm{n}^{\text {th }}$ Metallic Mean $\left(\boldsymbol{\delta}_{\mathbf{n}}\right)$, but its every geometric feature is the prototypical form of that Metallic Mean [6], [7], [8], [9].

The characteristic geometry of such Right Triangle having its catheti $\mathbf{1}$ and $\frac{\mathbf{n}}{\mathbf{2}}$, is resplendent with the corresponding $\mathrm{n}^{\text {th }}$ Metallic Mean $\left(\boldsymbol{\delta}_{\mathbf{n}}\right)$ embedded in its every geometric aspect.

For example, the remarkable expression of Golden Ratio in every geometric feature of $1: 2: \sqrt{5}$ triangle, including all its angles and side lengths, its 'Incenter-Excenters Orthocentric system', its Gergonne and Nagel triangles, and also the Nobbs points and the Gergonne line, various triangle centers as well as the Incircle of 1:2: $\sqrt{5}$ triangle, make this triangle the quintessential form of the Golden Ratio $(\varphi)$ and also of the fourth Metallic Mean $\left(\varphi^{3}\right)$. [7] 


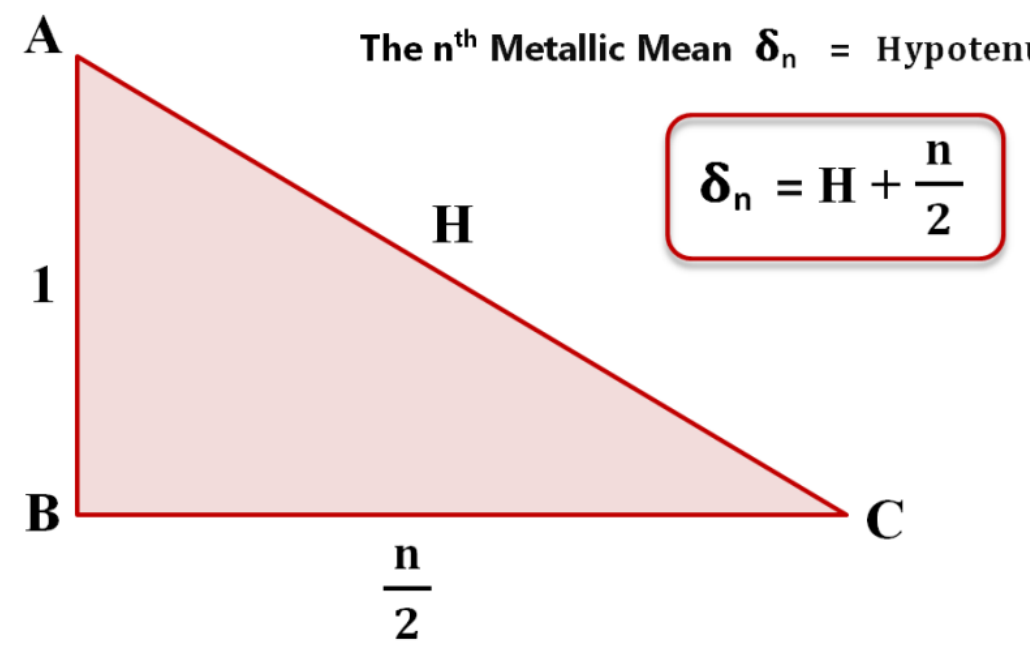

Figure 1: Generalised Right Triangle to represent any $\mathrm{n}^{\text {th }}$ Metallic Mean $\boldsymbol{\delta}_{\mathrm{n}}$

\section{MATHEMATICAL CORRELATIONS AMONG DIFFERENT METALLIC RATIOS :}

If $\mathbf{K}, \mathbf{m}$ and $\mathbf{n}$ are three positive integers such that $\mathbf{n}$ is the smallest of the three integers and $\frac{\mathbf{m n}+\mathbf{4}}{\mathbf{m}-\mathbf{n}}=\mathbf{k}$ then, it is observed that

$\frac{\boldsymbol{\delta}_{\mathrm{m}} \times \boldsymbol{\delta}_{\mathrm{n}}+\mathbf{1}}{\boldsymbol{\delta}_{\mathrm{m}}-\boldsymbol{\delta}_{\mathrm{n}}}=\boldsymbol{\delta}_{\mathrm{k}}$ where $\boldsymbol{\delta}_{\mathrm{k}}, \boldsymbol{\delta}_{\mathrm{m}}$ and $\boldsymbol{\delta}_{\mathrm{n}}$ are the $\mathrm{k}^{\text {th }}, \mathrm{m}^{\text {th }}$ and $\mathrm{n}^{\text {th }}$ Metallic Means respectively.

This explicit formula, among several other formulae those give the precise mathematical relations between different Metallic Means, has been recently published in the work mentioned in References [1] and [2].

\section{The "TRIADS" Of Metallic Means :}

The abovementioned explicit formula gives the "Triads" of Metallic Means as $\left[\boldsymbol{\delta}_{n}, \boldsymbol{\delta}_{\mathrm{m}}, \boldsymbol{\delta}_{\mathrm{k}}\right]$

Where $\frac{\mathbf{m n}+4}{\mathbf{m}-\mathbf{n}}=\mathbf{k}$ and $\frac{\mathbf{k n}+4}{\mathrm{k}-\mathrm{n}}=\mathbf{m}$

hence, $\frac{\boldsymbol{\delta}_{\mathrm{m}} \times \boldsymbol{\delta}_{\mathrm{n}}+\mathbf{1}}{\boldsymbol{\delta}_{\mathrm{m}}-\boldsymbol{\delta}_{\mathrm{n}}}=\boldsymbol{\delta}_{\mathrm{k}} \quad$ and also $\frac{\boldsymbol{\delta}_{\mathrm{k}} \times \boldsymbol{\delta}_{\mathrm{n}}+\mathbf{1}}{\boldsymbol{\delta}_{\mathrm{k}}-\boldsymbol{\delta}_{\mathrm{n}}}=\boldsymbol{\delta}_{\mathrm{m}}$

Moreover,

$$
\frac{\mathbf{k m}-\mathbf{4}}{\mathbf{k}+\mathbf{m}}=\mathbf{n} \quad \text { and } \quad \frac{\boldsymbol{\delta}_{\mathrm{k}} \times \boldsymbol{\delta}_{\mathrm{m}}-\mathbf{1}}{\boldsymbol{\delta}_{\mathrm{k}}+\boldsymbol{\delta}_{\mathrm{m}}}=\boldsymbol{\delta}_{\mathbf{n}}
$$


For example, if $n=6$, the three integers 6,11 and 14 satisfy the prerequisite $\frac{\mathbf{m n}+\mathbf{4}}{\mathbf{m}-\mathbf{n}}=\mathbf{k}$;

Hence, the three Merallic means $\boldsymbol{\delta}_{6}, \boldsymbol{\delta}_{11}$ and $\boldsymbol{\delta}_{14}$ form a Triad $\left[\boldsymbol{\delta}_{6}, \boldsymbol{\delta}_{11}, \boldsymbol{\delta}_{14}\right]$ such that :

$$
\frac{\boldsymbol{\delta}_{11} \times \boldsymbol{\delta}_{6}+\mathbf{1}}{\boldsymbol{\delta}_{11}-\boldsymbol{\delta}_{6}}=\boldsymbol{\delta}_{14} \quad \text { and also } \quad \frac{\boldsymbol{\delta}_{14} \times \boldsymbol{\delta}_{6}+\mathbf{1}}{\boldsymbol{\delta}_{14}-\boldsymbol{\delta}_{6}}=\boldsymbol{\delta}_{11} \quad \text { Also, } \frac{\boldsymbol{\delta}_{14} \times \boldsymbol{\delta}_{11}-\mathbf{1}}{\boldsymbol{\delta}_{14}+\boldsymbol{\delta}_{11}}=\boldsymbol{\delta}_{\mathbf{6}}
$$

Noticeably, $\mathbf{n}=\mathbf{6}$ forms such multiple triads:

\begin{tabular}{|l|l|l|l|l|l|l|l|l|}
\hline $\mathrm{n}$ & 6 & 6 & 6 & 6 & 6 & 6 & 6 & 6 \\
\hline $\mathrm{m}$ & 7 & 8 & 10 & 11 & 14 & 16 & 26 & 46 \\
\hline $\mathrm{k}$ & 46 & 26 & 16 & 14 & 11 & 10 & 8 & 7 \\
\hline
\end{tabular}

: Shaded Triads have been exemplified above.

And, just like $\mathbf{n}=\mathbf{6}$ exemplified above, every integer forms such multiple triads:

For example, $\mathbf{n}=\mathbf{1 0}$

\begin{tabular}{|l|l|l|l|l|l|l|l|l|}
\hline $\mathrm{n}$ & 10 & 10 & 10 & 10 & 10 & 10 & 10 & 10 \\
\hline $\mathrm{m}$ & 11 & 12 & 14 & 18 & 23 & 36 & 62 & 114 \\
\hline $\mathrm{k}$ & 114 & 62 & 36 & 23 & 18 & 14 & 12 & 11 \\
\hline
\end{tabular}

\section{Noticeably, Odd $\mathbf{n}$ forms Fewer Triads}

\begin{tabular}{|l|l|l|l|l|l|l|l|l|}
\hline $\mathrm{n}$ & 5 & 5 & 5 & 5 & 5 & 5 & 5 & 5 \\
\hline $\mathrm{m}$ & 6 & 34 & & & & & & \\
\hline $\mathrm{k}$ & 34 & 6 & & & & & & \\
\hline
\end{tabular}

It may be noticed from above Tables that every $\mathrm{n}^{\text {th }}$ Metallic Mean can give precise values of various Metallic Means by the formula $\frac{\boldsymbol{\delta}_{\mathrm{m}} \times \boldsymbol{\delta}_{\mathrm{n}}+\mathbf{1}}{\boldsymbol{\delta}_{\mathrm{m}}-\boldsymbol{\delta}_{\mathrm{n}}}=\boldsymbol{\delta}_{\mathrm{k}}$, maximum upto $\left(\mathrm{n}^{2}+\mathrm{n}+4\right)^{\mathrm{th}}$ Metallic Mean:

$\mathbf{m}_{\max }=\mathbf{k}_{\max }=\left(n^{2}+n+4\right)$ 
Also noticeably, the Even Integers ( Even $\mathrm{n}_{\mathrm{s}}$ ) form comparatively more Triads than the Odd $\mathrm{n}_{\mathrm{s}}$. Several such patterns about these Triads of Metallic Means have been discussed in detail in Reference [2]. Here, let us consider the classical correspondence of the abovementioned Formula and the TRIADS with the Geometry of Metallic Ratios.

Remarkably, the abovementioned Triads of Metallic Means can be represented geometrically, as shown below.

For instance, the Triad [ $\left.\boldsymbol{\delta}_{\mathbf{n}}, \boldsymbol{\delta}_{\mathbf{m}}, \boldsymbol{\delta}_{\mathbf{k}}\right]$ is illustrated geometrically in following Figure $\mathbf{2}$.

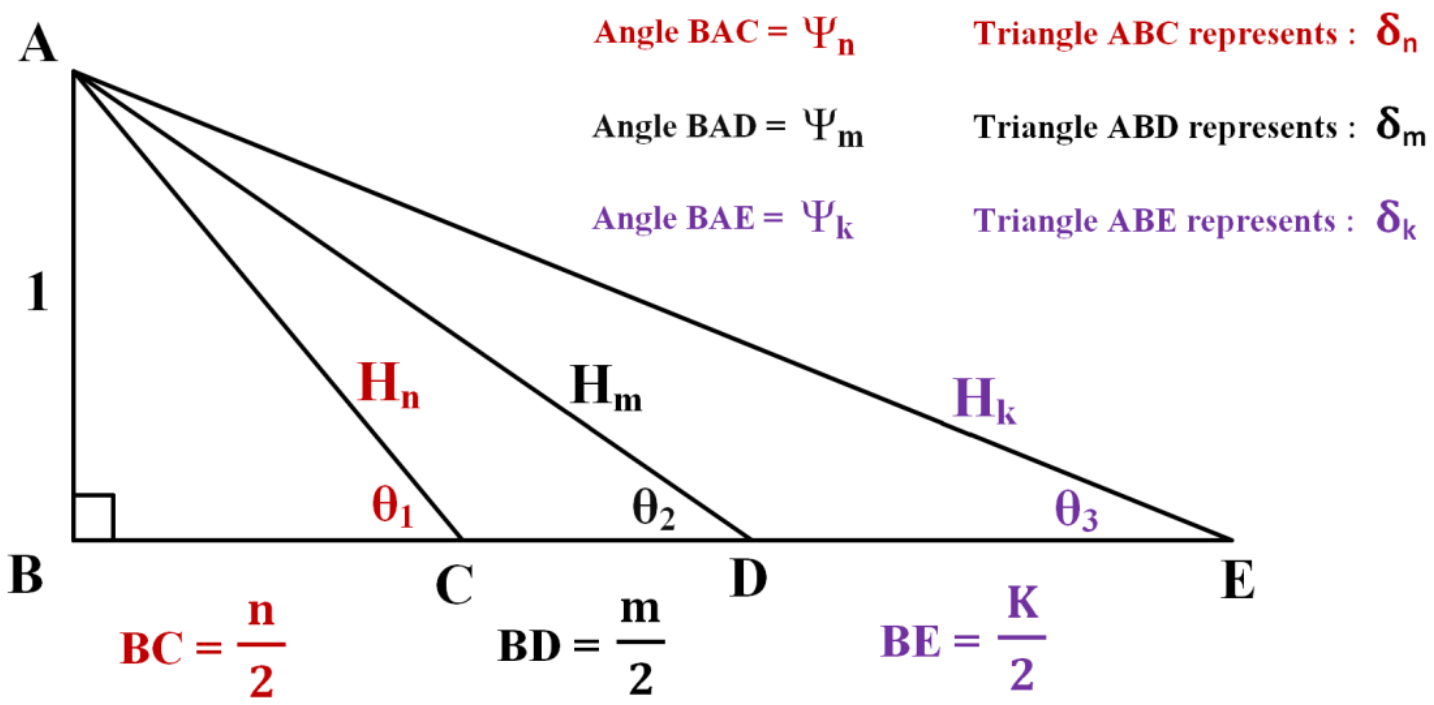

Figure 2: Three Right Triangles representing the "Triad of Metallic Means"

Remarkably, in above Figure 2: if the three Metallic Means $\boldsymbol{\delta}_{\mathbf{n}}, \boldsymbol{\delta}_{\mathbf{m}}$ and $\boldsymbol{\delta}_{\mathbf{k}}$ constitute a $\operatorname{Triad}$ as $\frac{\mathbf{m n}+\mathbf{4}}{\mathbf{m}-\mathbf{n}}=\mathbf{k}$, then

$\boldsymbol{\theta}_{1}=\boldsymbol{\theta}_{2}+\boldsymbol{\theta}_{3} \quad$ ( and also $\left.\Psi_{\mathrm{n}}+\mathbf{9 0 ^ { 0 }}=\boldsymbol{\Psi}_{\mathrm{m}}+\boldsymbol{\Psi}_{\mathrm{k}}\right)$

In other words,

$\arctan \frac{2}{n}=\arctan \frac{2}{m}+\arctan \frac{2}{k}$

Solving it gives the correlations: $\frac{\mathbf{m n}+\mathbf{4}}{\mathbf{m}-\mathbf{n}}=\mathbf{k}$ and $\frac{\mathbf{k n}+\mathbf{4}}{\mathbf{k}-\mathbf{n}}=\mathbf{m}$

And also $\frac{\mathbf{k m}-\mathbf{4}}{\mathbf{k}+\mathbf{m}}=\mathbf{n}$

And hence satisfy the prerequisite for $\frac{\boldsymbol{\delta}_{\mathrm{m}} \times \boldsymbol{\delta}_{\mathrm{n}}+\mathbf{1}}{\boldsymbol{\delta}_{\mathrm{m}}-\boldsymbol{\delta}_{\mathrm{n}}}=\boldsymbol{\delta}_{\mathrm{k}}$ and $\frac{\boldsymbol{\delta}_{\mathrm{k}} \times \boldsymbol{\delta}_{\mathrm{n}}+\mathbf{1}}{\boldsymbol{\delta}_{\mathrm{k}}-\boldsymbol{\delta}_{\mathrm{n}}}=\boldsymbol{\delta}_{\mathrm{m}}$

And also $\frac{\boldsymbol{\delta}_{\mathrm{k}} \times \boldsymbol{\delta}_{\mathrm{m}}-\mathbf{1}}{\boldsymbol{\delta}_{\mathrm{k}}+\boldsymbol{\delta}_{\mathrm{m}}}=\boldsymbol{\delta}_{\mathbf{n}}$ 
Moreover, the Hypotenuses of these Triad-Triangles: $\mathbf{H}_{\mathbf{n}}, \mathbf{H}_{\mathbf{m}}$ and $\mathbf{H}_{\mathbf{k}}$ in Figure $\mathbf{2}$ exhibit following relations.

$\frac{\mathbf{H}_{\mathrm{k}}}{\mathbf{H}_{\mathrm{m}}}=\frac{2}{\mathbf{m}-\mathbf{n}} \times \mathbf{H}_{\mathrm{n}}$

Simplying this, we get $\frac{\mathrm{k}^{2}+4}{\mathrm{~m}^{2}+4}=\frac{\mathrm{n}^{2}+4}{(\mathrm{~m}-\mathrm{n})^{2}}$

And solving it gives $\mathbf{k}=\frac{\mathbf{m n}+\mathbf{4}}{\mathbf{m}-\mathbf{n}}$; which is the prerequisite for formation of a Triad $\left[\boldsymbol{\delta}_{\mathbf{n}}, \boldsymbol{\delta}_{\mathbf{m}}, \boldsymbol{\delta}_{\mathbf{k}}\right]$

Moreover, entire geometry of such Triad-Triangles is resplendent with the precise correlation among the three Metallic Means $\boldsymbol{\delta}_{\mathbf{n}}, \boldsymbol{\delta}_{\mathbf{m}}$ and $\boldsymbol{\delta}_{\mathbf{k}}$. Following intriguing relations are observed in above Figure 2 . Consider the larger acute angles of the three triangles;

$$
\begin{aligned}
& \Psi_{\mathrm{m}}+\Psi_{\mathrm{k}}=2 \arctan \boldsymbol{\delta}_{\mathrm{n}} \\
& \Psi_{\mathrm{m}}-\Psi_{\mathrm{n}}=2 \arctan \frac{1}{\delta_{\mathrm{k}}} \\
& \Psi_{\mathrm{k}}-\Psi_{\mathrm{n}}=2 \arctan \frac{1}{\delta_{\mathrm{m}}}
\end{aligned}
$$

Similarly, $\arctan \frac{1}{\delta_{\mathrm{n}}}=\arctan \frac{1}{\delta_{\mathrm{m}}}+\arctan \frac{1}{\delta_{\mathrm{k}}}$

simplifying which we get : $\frac{\mathbf{k m}-\mathbf{4}}{\mathbf{k}+\mathbf{m}}=\mathbf{n}$ and hence $\frac{\boldsymbol{\delta}_{\mathrm{k}} \times \boldsymbol{\delta}_{\mathrm{m}}-\mathbf{1}}{\boldsymbol{\delta}_{\mathrm{k}}+\boldsymbol{\delta}_{\mathrm{m}}}=\boldsymbol{\delta}_{\mathbf{n}}$

And,

$\arctan \frac{1}{\delta_{\mathrm{n}}}+\arctan \frac{1}{\delta_{\mathrm{m}}}+\arctan \frac{1}{\delta_{\mathrm{k}}}=2 \arctan \frac{1}{\delta_{\mathrm{n}}}=\left(\theta_{1}\right)=\left[\theta_{2}+\theta_{3}\right]$

$=\arctan \frac{2}{\mathrm{n}}=\left[180^{\circ}-\left(\Psi_{\mathrm{m}}+\Psi_{\mathrm{k}}\right)\right]$

$=$ Half of the Smaller Acute Angle of the Pythagorean Triple associated with the Right Triangle for $\boldsymbol{\delta}_{\mathrm{n}}$ (Described in following Section) 
Similarly,

$\arctan \boldsymbol{\delta}_{\mathrm{n}}+90^{0}=\arctan \boldsymbol{\delta}_{\mathrm{m}}+\arctan \boldsymbol{\delta}_{\mathrm{k}}$

And,

$\arctan \boldsymbol{\delta}_{\mathrm{n}}+\arctan \boldsymbol{\delta}_{\mathrm{m}}+\arctan \boldsymbol{\delta}_{\mathrm{k}}=\Psi_{\mathrm{n}}+180^{0}=\left(\Psi_{\mathrm{m}}+\Psi_{\mathrm{k}}\right)+90^{0}$

Another interesting aspect of this geometry of Metallic Means is its classical correspondence with Primitive Pythagorean Triples. Each of the Right Triangles representing various Metallic Means, and hence the abovementioned Triads of Metallic Means are associated with a particular primitive Pythagorean triple, depending upon the value of $\mathbf{n}$. For example, Right Triangle for $6^{\text {th }}$ Metallic Mean $\left(\boldsymbol{\delta}_{6}\right)$, and hence all Triads with $n=6$, are associated with 3-4-5 Pythagorean Triple. For instance, consider the Triad $\left[\boldsymbol{\delta}_{6}, \boldsymbol{\delta}_{11}, \boldsymbol{\delta}_{14}\right]$. If this Triad is constructed geometrically, as in above Figure 2, then it is observed that:

$\mathbf{2 \theta}_{\mathbf{1}}=\left(\boldsymbol{\theta}_{1}+\boldsymbol{\theta}_{2}+\boldsymbol{\theta}_{3}\right)=$ The Smaller Acute Angle of 3-4-5 Pythagorean Triangle i.e. $\arctan \frac{\mathbf{3}}{\mathbf{4}}$

$\mathbf{2} \Psi_{n}-\mathbf{9 0}^{\circ}=\left(\Psi_{n}+\Psi_{m}+\Psi_{k}\right)-\mathbf{1 8 0}^{\circ}=$ The Larger Acute Angle of 3-4-5 Pythagorean Triangle i.e. $\arctan \frac{\mathbf{4}}{3}$

Likewise, Right Triangle for $3^{\text {rd }}$ Metallic Mean (and all Triads with $n=3$ ), or Right Triangle for $10^{\text {th }}$ Metallic Mean (and Triads with $n=10$ ), are all related to 5-12-13 Pythagorean Triple, and so on.

Several such intriguing properties of Metallic Means and their abovementioned TRIADS are described in details in the works mentioned below in the References. For instance, the presence of these TRIADS of Metallic Ratios in Pascal's Triangle [10]; these TRIADS are found to be closely associated with Pythagorean Triples and Pythagorean Primes [2][11]; the geometric substantiation of Metallic Ratios and their TRIADS [2] [6] [7] [8] [9]; and special positions of Integers 3, 6 and 9 in the realm of Metallic Means [2][12]. Further, all imperical formulae those provide the precise mathematical relations between different Metallic Means are described in the work mentioned in Reference [1].

\section{Conclusion:}

This paper synergized the geometry of all Metallic Means and the mathematical formula that provides the precise correlations between different Metallic Ratios. The synergy between these two aspects of Metallic Ratios provided the geometric substantiation of the "TRIADS of Metallic Means" in an intriguing manner, as communicated in this paper.

\section{References:}

[1] Rajput, Chetansing (2021). Metallic Ratios : Beyond the Golden Ratio; The Mathematical Relationships between different Metallic Means. JOURNAL OF ADVANCES IN MATHEMATICS, 20, 158-166. https://doi.org/10.24297/jam.v20i.9023 
[2] Rajput, Chetansing (2021). "Metallic Means : Beyond the Golden Ratio, New Mathematics and Geometry of all Metallic Ratios based upon Right Triangles, The Formation of the Triples of Metallic Means, And their Classical Correspondence with Pythagorean Triples and $p \equiv 1$ (mod 4) Primes, Also the Correlation between Metallic Numbers and the Digits 36 9", JOURNAL OF ADVANCES IN MATHEMATICS, 20, 250-266. https://doi.org/10.24297/jam.v20i.9056

[3] Vera W. de Spinadel (1999). The Family of Metallic Means, Vismath 1(3) from Mathematical Institute of Serbian Academy of Sciences and Arts.

[4] Weisstein, Eric W. "Table of Silver means". MathWorld.

[5] "An Introduction to Continued Fractions: The Silver Means", maths.surrey.ac.uk.

[6] Rajput, Chetansing (2021). "A Right Angled Triangle for each Metallic Mean". Journal of Advances in Mathematics. 20: 32-33. https://en.wikipedia.org/wiki/Metallic mean\#cite note-15

[7] Rajput, Chetansing (2021). Golden Ratio. JOURNAL OF ADVANCES IN MATHEMATICS, 20, 19-42. https://doi.org/10.24297/jam.v20i.8945

[8] Rajput, Chetansing (2021). Metallic Means and Right Triangles: The Geometric Substantiation of all Metallic Ratios JOURNAL OF ADVANCES IN MATHEMATICS, 20, 167-173. https://doi.org/10.24297/jam.v20i.9029

[9] Rajput, Chetansing (2021). Golden Ratio and other Metallic Means: The Geometric Substantiation of all Metallic Ratios with Right Triangles. JOURNAL OF ADVANCES IN MATHEMATICS, 20, $174-187$. https://doi.org/10.24297/jam.v20i.9034

[10] Rajput, Chetansing (2021). Metallic Ratios and Pascal's Triangle : Triads of Metallic Means in the Pascal's Triangle. JOURNAL OF ADVANCES IN MATHEMATICS, 20, 167-173. https://doi.org/10.24297/jam.v20i.9078

[11] Rajput, Chetansing (2021). Metallic Ratios, Pythagorean Triples \& Pythagorean Primes: New Mathematics and Geometry of Metallic Means, Metallic Numbers, Right Triangles and the Pythagoras Theorem. JOURNAL OF ADVANCES IN MATHEMATICS, 20, 167-173. https://doi.org/10.24297/jam.v20i.9075

[12] Rajput, Chetansing (2021). Metallic Ratios and the Digits 36 9, Mathematical Relations between different Metallic Means,_And the Special Significance of Digits 3, 6, 9 in the realm of Metallic Numbers. JOURNAL OF ADVANCES IN MATHEMATICS, 20, 167-173. https://doi.org/10.24297/jam.v20i.9076

\begin{tabular}{|l|l|}
\hline Select Lecture Videos of Author: & Contacts: \\
1) https://youtu.be/vBfVDaFnA2k & Website: https://goldenratiorajput.com/ \\
2) https://youtu.be/74uF4sBqYjs & Email: chetansingkrajput@gmail.com \\
3) https://youtu.be/raosniXwRhw & Email: chetansingkrajput1129@gmail.com \\
4) https://youtu.be/Qh2B1tMl8Bk & Contacts: (+91) 7057521129 \\
\hline
\end{tabular}

